\title{
Mobile and Hard-to-Reach Voters
}

\author{
Christian Hoops ${ }^{1}$, Tobias Michael ${ }^{2}$ \\ ${ }^{1}$ Ipsos Public Affairs, Hamburg, ${ }^{2}$ Ipsos Public Affairs, Berlin \\ Keywords: voters, rcs, mobile, landline, elections, cati \\ https://doi.org/10.29115/SP-2015-0020
}

\section{Survey Practice}

Vol. 8, Issue 4, 2015

\begin{abstract}
By taking into account mobile device samples to not exclude Mobile-Only respondents, a better representation of the general population can be obtained. This leads to more accu-rate analyses and findings that closely reflect reality. Data are collected that provides more representative and dynamic analyses by using the Rolling Cross-Section Design (see Johnston/Brady 2002), which takes a crosssection and distributes interviewing in a controlled way over time. A strict contact scheme with a high contact density allows even Hard-to-Reach populations to be taken into account appropriately in the random sample. Minimal deviations from the sample and general population will be corrected at the conclusion by a dual frame assessment system developed by the Association of German Market and Social Researchers.

This paper investigates how the inclusion of Mobile-Only, Mostly-Mobile and Hard-to-Reach voters affects the estimates of voting behavior within the context of Germany. It be-gins by showing that these groups differ from the general population in terms of age, sex, employment, school graduation and income. Furthermore, there are significant differences in their political issues priorities and participation. Especially Hard-to-Reach voters have a higher voting intention and should be conducted.
\end{abstract}

Different Voting Behavior from the General Population

\section{Introduction}

Not only have the general conditions for political opinion formation evolved, but conventional opinion polls are increasingly under pressure due to technological changes and shifts in voter behavior. The increasing prevalence of mobile phones poses considerable challenges for classic telephone surveys. The number of landline connections is declining, and the latest studies estimate the proportion of people who can only be reached using their mobile phone (Mobile-Only) to be around 31 percent of the European population. There are differences between countries, e.g., Sweden 2 percent, Germany 10 percent and Finland 85 percent (Arbeitskreis Deutscher Markt- und Sozialforschungsinstitute e.V. 2012; European Commission 2014). Of those who still have a landline, there are numerous individuals who are mainly reachable via their mobile phones (Mostly-Mobile) (Häder, Häder, and Kühne 2012). The difficulty lies in the fact that those exclusively using mobile phones differ systematically from people who only have a landline. Our survey meets these challenges head-on.

\section{Combination of Landline and Mobile Samples}

Since a considerable part of the eligible voters are either predominantly or exclusively accessible on a mobile phone, random surveys conducted through landlines are now supplemented by random sampling through mobile devices. 
This allows the so-called Mostly-Mobile and/or Mobile-Only to be represented accordingly in the sample (Hoffmann 2007). In the research, this is called the dual frame approach. The application of this approach produces data that are more representative of the general population.

There are numerous publications dealing with the Mobile-Only population. The Mobile-Only group is overwhelmingly male, young (Graeske and Kunz 2009), unmarried, uneducated, and low income earners (Keeter 2006). Additionally, this group is mostly migrants (Pennay 2010), students, and the unemployed as well as recent retirees (Link et al. 2007). In Germany, there is an especially large proportion of Mobile-Onlys in the new states (Hunsicker and Schroth 2007).

Mobile-Onlys also differ significantly in terms of participation. According to a survey of the U.S. electorate in 2004, Mobile-Onlys voted more often for John Kerry and most had a liberal world view. The most important topics named for elections were most often taxes and work, whereas terrorism and the situation in Iraq was rarely named as a concern (Keeter 2006). MobileOnlys in an Australian survey were more concerned with work, climate change and immigration as the most important problems for the country. In contrast, health was not as important (Pennay 2010). Additionally, Mobile-Onlys are less interested in politics (cf. Hunsicker and Schroth 2007) and do not follow elections closely. They are more likely to report that they are too busy to vote and to believe their vote will not make a difference. Mobile-Onlys are also more likely to be first-time voters (Keeter et al. 2007). Less is known about the Mostly-Mobiles. There are also no worldwide established scales to identify this dual user accordingly.

Since only one person is surveyed per household, the random sampling process delivers a household sampling. ${ }^{1}$ In order to correct any effects on the analysis caused by the design, the cases receive a pre-design assessment during the later evaluation. This is calculated using the number of "target persons in the household" $\left(T_{\mathrm{HH}}\right)$, the "target persons who use the mobile phone called" $\left(T_{\text {Mobil }}\right)$, the "landline numbers over which the household can be reached" ( $\left.k \_i^{L}\right)$, and the "mobile numbers over which the respondent can be reached" ( $\left.k \_i^{C}\right)$. This makes it possible to determine the probability of the $i$-th person being included in the sample:

$$
\pi \_i \approx k \_i^{L} \cdot \frac{m^{L}}{M^{L}} \cdot \frac{1}{T \_H H}+k \_i^{C} \cdot \frac{m^{C}}{M^{C}} \cdot \frac{1}{T \_M o b i l}
$$

1 Every household in the general population that has a landline or mobile phone connection will have the chance to be part of the sample. Due to the heterogeneous number of mobile telephones and landlines per household, the elements of the general population can in part have a greatly varied inclusion probability in the sample. For the sake of efficiency, the institute of the Association of German Market and Social Researchers recommends a mixture of 60-70 percent landline interviews. 
Besides being dependent on the realized sample size for landlines $\left(m^{L}\right)$ and for the mobile network $\left(m^{C}\right)$ this value is also dependent on the amount of landline numbers $\left(M^{L}\right)$ and/or mobile phone numbers $\left(M^{C}\right)$ in the sampling group (Gabler and Ayhan 2007). After both samples have been proportioned appropriately, which is necessary to ensure that those with only a landline (Landline-Only) are not disproportionately represented in the sample in comparison to the Mobile-Onlys_, an additional evaluation is carried out to address the typical characteristics. This way the structure of the sample is adjusted to fit with official statistics. The combination of landline and mobile samples and a high contact density increase the cardinality of the sample space and yields to higher data quality.

\section{Descriptive Analyses}

The data was collected by Ipsos in April/May 2013 as a daily rolling crosssection (RCS)-survey ${ }^{2}$ of German's eligible voting population. Only fresh numbers were used (no panelists etc.) and no incentives were provided to achieve a response rate of 25 percent. ${ }^{3}$ Using the additional mobile device sample, the opinion of the Mobile-Only group is also surveyed. Moreover, the class of Mostly-Mobiles, who have a landline phone and are "exclusively reachable over mobile devices", can also be mapped out better. Out of all the respondents, a proportion of 14.8 percent are Mobile-Only and 6 percent Mostly-Mobile. Furthermore, we analyzed the interviews with people that needed more than six dial attempts to be interviewed (Hard-to-Reach).

Both mobile types have a greater tendency to be male and much younger than the general sample (see Table 1). The percentage of men in the Mostly-Mobile group is higher than that in the Mobile-Only group. Additionally, they are such as the Hard-to-Reach significantly more likely to be between 30 and 49 years old.

The Mobile-Only group is found more than double as frequently in the group of those under the age of 30 . Mobile-Onlys are also most often those completing training or retraining contrary to the Hard-to-Reach group. The Mobile-Only is also more likely to be out of work and is usually relatively uneducated. All three groups are more likely to be fully employed. However, the Mostly-Mobile and Hard-to-Reach groups are seldom unemployed. The number of high school graduates is distributed similarly to the distribution in the sample.

\footnotetext{
2 In a classical RCS-survey, the initial sample will be randomly broken down into partial samples, so-called "replicates." These replicates will then be sent out into the field on a randomly chosen survey day and processed according to a previously defined contact scheme. This means that the same rule apply to each replicate. As a result, partial samples start to overlap each other during their time in the field (Johnston and Brady 2002). This strict contact protocol ensures that each daily sample is made up of a consistent percentage of Easy-to-Reach and Hard-to-Reach respondents within the individual replicates.

3 For a description of the methodology, please see http://www.ipsos.de/assets/files/presse/2013/publikationen/FactSheet-RCS.pdf or email Christian Hoops at christian.hoops@ipsos.com.
} 
Table 1 Age and sex per mobile type and reachability.

\begin{tabular}{|c|c|c|c|c|}
\hline & Mobile-Only & Mostly-Mobile & Hard-to-Reach & Total \\
\hline Men & $61.6 \% * *[\wedge 4]$ & $75.2 \% * *$ & $52.7 \%$ & $51.5 \%$ \\
\hline Up to 29 years & $34.4 \% * *$ & $27.8 \%^{* *}$ & $12.7 \%^{* *}$ & $16.8 \%$ \\
\hline $30-49$ years & $39.1 \% * *$ & $46.6 \% * *$ & $43.2 \%{ }^{* *}$ & $34.0 \%$ \\
\hline 50 years or older & $26.5 \%^{* *}$ & $25.5 \%^{* *}$ & $44.1 \%^{* *}$ & $49.2 \%$ \\
\hline $\mathrm{N}$ & 312 & 126 & 437 & 2102 \\
\hline
\end{tabular}

Table 2 Household size and income per mobile type.

\begin{tabular}{llll}
\hline & Mobile-Only & Mostly-Mobile & Total \\
Up to 2,000 euros & $70.4 \%^{* *}$ & $43.3 \%^{*}$ & $50.7 \%$ \\
$2,000-5,000$ euros & $26.9 \%^{* *}$ & $45.5 \%$ & $41.5 \%$ \\
More than 5,000 euros & $2.7 \%^{* *}$ & $11.3 \%$ & $7.8 \%$ \\
& & & 2.45 \\
\hline
\end{tabular}

Table 3 Political participation and voting behavior per mobile type and reachability.

\begin{tabular}{lllll}
\hline & Mobile-Only & Mostly-Mobile & Hard-to-Reach & Total \\
Confidence in voting intention & 1.74 & 1.99 & 1.87 & 1.85 \\
Political interest & $3.07^{* *}$ & 2.82 & 2.71 & 2.75 \\
Intention to vote & $1.94^{* *}$ & $1.84^{* *}$ & $1.44^{* *}$ & 1.57 \\
\hline
\end{tabular}

There are significant differences in household size and household income. Mobile-Only households tend to earn low wages, whereas the private households of Mostly-Mobiles tend to be markedly better off financially (see Table 2).

Compared to the general sample, the political interests of both mobile types are less pronounced, which is shown by the higher averages in Table 3 under this characteristic. This is also consistent with the intention to vote. Mobile-Onlys are relatively sure of their voting decisions, whereas the Mostly-Mobiles are more indecisive. The Hard-to-Reach group has a very high intention to vote. From this it follows that a high contact density should be reached in electoral researches, for example, to make good election predictions (cf. Hoops 2015).

For Mobile-Onlys, unemployment is the greatest political problem in Germany (see Table 4), presumably while they themselves are often unemployed (cf. Table 5). Similarly, the question of integration and migration is more often 
Table 4 Important political issues in Germany per mobile type.

\begin{tabular}{llll}
\hline & Mobile-Only & Mostly-Mobile & Total \\
Unemployment & $21.9 \%^{* *}$ & $15.4 \%$ & $14.9 \%$ \\
Educational policy & $3.2 \%$ & $8.1 \%$ & $5.3 \%$ \\
Energy transition & $3.5 \%$ & $4.7 \%$ & $4.2 \%$ \\
Euro Crisis & $15.5 \%$ & $20.8 \%$ & $18.4 \%$ \\
Integration/migration & $10.2 \%^{*}$ & $3.3 \%$ & $5.6 \%$ \\
Low wages & $5.7 \%$ & $6.2 \%$ & $6.3 \%$ \\
Poverty of the retired/elderly & $1.6 \%$ & $3.5 \%$ & $3.4 \%$ \\
Social inequality & $7.7 \%$ & $8.2 \%$ & $9.4 \%$ \\
Taxes & $3.8 \%$ & $4.4 \%$ & $3.4 \%$ \\
\hline
\end{tabular}

Table 5 Employment and school graduation per mobile type and reachability.

\begin{tabular}{|c|c|c|c|c|}
\hline & Mobile-Only & Mostly-Mobile & Hard-to-Reach & Total[^6] \\
\hline Fully employed & $49.6 \%^{* *}$ & $74.9 \%^{* *}$ & $51.2 \%^{* *}$ & $43.2 \%$ \\
\hline Partially employed & $11.2 \%$ & $5.1 \%^{* *}$ & $14.3 \%$ & $12.5 \%$ \\
\hline In training/retraining & $16.4 \%^{* *}$ & $12.3 \%$ & $6.9 \% * *$ & $9.6 \%$ \\
\hline Retired & $10.0 \%^{* *}$ & $6.8 \% * *$ & $24.0 \% *$ & $27.7 \%$ \\
\hline Unemployed & $12.9 \%^{* *}$ & $0.9 \% * *$ & $4.6 \% * *$ & $7.1 \%$ \\
\hline School dropouts & $3.3 \%$ & $1.0 \%$ & $1.2 \%^{* *}$ & $2.6 \%$ \\
\hline Graduated from high schools & $61.1 \%$ & $54.9 \%$ & $55.6 \%$ & $55.6 \%$ \\
\hline Prepared for university of applied sciences & $10.3 \%$ & $12.2 \%$ & $13.2 \%$ & $12.8 \%$ \\
\hline College-bound graduates & $25.4 \%^{*}$ & $31.9 \%$ & $29.9 \%$ & $29.1 \%$ \\
\hline
\end{tabular}

given as a main issue in comparison to the general sample. Poverty among the elderly, the Euro Crisis, and bad educational policies are mentioned less often in contrast.

Our results on unemployment, taxes, and integration/migration are similar to those observed by Keeter (2006) in the United States and Pennay (2010) in Australia. The results differ only on environment policy. The Mostly-Mobiles are more likely to designate the Euro Crisis as the biggest problem. Educational, environmental, and tax policies are also mentioned more frequently. This is presumably due to differences in income and education. Integration and migration were named by Mostly Mobiles less often.

In summary, we can conclude that our socio-demographic analysis results are consistent with previous analyses (Link et al. 2007). Additionally, it can be seen that Mobile-Only, Mostly-Mobile and Hard-to-Reach groups differ from the general population in their levels of political participation, opinion formation and voting behavior (see Table 6). 
Table 6 Voting behavior depending on mobile status and reachability.

\begin{tabular}{|c|c|c|c|c|c|}
\hline & Mobile-Only & Mostly-Mobile & Easy-to-Reach & Hard-to-Reach & Total \\
\hline CDU/CSU & $46.6 \%$ & $31.3 \% * *$ & $43.2 \% * *$ & $48.4 \%^{* *}$ & $44.3 \%$ \\
\hline SPD & $19.9 \% * *$ & $25.5 \%$ & $26.1 \%^{* *}$ & $18.1 \%^{* *}$ & $24.3 \%$ \\
\hline B90/Greens & $17.5 \%$ & $16.3 \%$ & $15.3 \%^{*}$ & $18.8 \%^{*}$ & $16.1 \%$ \\
\hline FDP & $2.3 \%$ & $8.5 \%^{* *}$ & $3.2 \%^{* *}$ & $5.9 \% * *$ & $3.8 \%$ \\
\hline The Lefts & $4.6 \%$ & $1.8 \%$ & $4.8 \%$ & $2.5 \%$ & $4.3 \%$ \\
\hline Pirate Party & $3.5 \%$ & $2.2 \%$ & $2.5 \%^{* *}$ & $0.2 \%^{* *}$ & $2.0 \%$ \\
\hline AfD & $2.7 \%$ & $3.3 \%$ & $1.8 \%$ & $3.1 \%$ & $2.1 \%$ \\
\hline $\mathrm{N}$ & 312 & 126 & 1665 & 437 & 2102 \\
\hline
\end{tabular}

The Mobile-Only group has a greater, but non-significant, tendency to vote for the CDU/CSU, B90/Greens, Pirate Party and AfD. Mostly-Mobiles are more often FDP and CDU/CSU voters. Furthermore, it can be seen that the proportion of CDU/CSU, B90/Greens and FDP voters is increased in the Hard-to-Reach group. This makes the collection of mobile device samples and Hard-to-Reach populations in electoral research indispensable for the generation of representative conclusions.

\section{Conclusion}

Our paper reports on a survey where landline and mobile device samples were used for the first time in conjunction with each other in a RCS-design. It allows new knowledge to surface about relatively unknown groups such as the Mostly-Mobiles voters. This population is mainly made up of middle-aged, well-educated, and higher income males with relatively low levels of political participation.

Since the Mobile-Only and Mostly-Mobile group deviate considerably from the general population, additional surveys over mobile devices are essential for a representative analysis. The RCS-design as a survey with a high contact density, on the other hand, decreases the variance of selection probability since even Hard-to-Reach subpopulations are reached more often in comparison to other election surveys. The Hard-to-Reach group shows an overall high voting intention and is essential to achieve a high cardinality to create a high data quality. From this, it follows that dual frame studies with a high contact density should be recommended in the field of electoral research. 


\section{REFERENCES}

Arbeitskreis Deutscher Markt- und Sozialforschungsinstitute e.V. 2012. "ADM-Forschungsprojekt „Dual-Frame-Ansätze“.” https://www.adm-ev.de/index.php?id=forschungsprojekte.

European Commission. 2014. "E-Communications and Telecom Single Market Household Survey Report.” Special Eurobarometer 414. http://ec.europa.eu/public_opinion/archives/ebs/ ebs_414_en.pdf.

Gabler, S., and Ö. Ayhan. 2007. "Gewichtung Bei Erhebungen Im Festnetz Und Über Mobilfunk: Ein Dual Frame.” In Mobilfunktelefonie - Eine Herausforderung Für Die Umfrageforschung, edited by S. Gabler and S. Häder, 13. ZUMA-Nachrichten.

Graeske, J., and T. Kunz. 2009. "Stichprobenqualität Der CELLA-Studie Unter Besonderer Berücksichtigung Der Mobile-Onlys.” In Telefonbefragungen Über Das Mobilfunknetz. Konzept, Design Und Umsetzung Einer Strategie Zur Datenerhebung, edited by M. Häder and S. Häder. Wiesbaden.

Häder, S., M. Häder, and M. Kühne. 2012. "Telephone Surveys in Europe.” Research and Practice.

Hoffmann, H. 2007. “Kombinierte Stichproben Für Telefonumfragen - Ansätze in Europa.” In Mobilfunktelefonie. Eine Herausforderung Für Die Umfrageforschung, edited by S. Gabler and S. Häder, 13. ZUMA-Nachrichten.

Hoops, C. 2015. Prognose-Almanach Der Deutschen Wablforschung. BoD, Norderstedt.

Hunsicker, S., and Y. Schroth. 2007. "Die Kombination von Mobilfunk- Und Festnetz-Stichproben Eine Praktische Anwendung Des Dual-Frame-Ansatzes.” Methoden-Daten-Analysen 1 (2): 161-82. Johnston, R., and H. Brady. 2002. “The Rolling Cross-Section Design.” Electoral Studies 21 (2): 283-95.

Keeter, S. 2006. "The Impact of Cell Phone Noncoverage Bias on Polling in the 2004 Presidential Election.” Public Opinion Quarterly 70 (1): 88-98.

Keeter, S., C. Kennedy, A. Clark, T. Tompson, and M. Mokrzycki. 2007. "What's Missing from National Landline RDD Surveys? The Impact of the Growing Cellonly Population.” Public Opinion Quarterly 71 (5): 772-92.

Link, M., M. Battaglia, M. Frankel, L. Osborn, and A. Mokdad. 2007. "Reaching the U.S. Cell Phone Generation. Comparison of Cell Phone Survey Results with Ongoing Landline Telephone Survey.” Public Opinion Quarterly 71 (5): 814-39.

Pennay, D. 2010. "Profiling the Mobile-Phone-Only Population. Results from a Dual-Frame Telephone Survey Using a Landline and Mobile Phone Sample Frame.” Australian Consortium for Social and Political Research Incorporated Social Science Methodology Conference Book, Sydney. 